\title{
O uso da própolis como coadjuvante ao tratamento periodontal
}

\author{
The use of propolis as an adjunct to periodontal treatment \\ El uso de propóleo como complemento del tratamiento periodontal
}

\section{Resumo}

A doença periodontal (DP) é definida como uma infecção de natureza polimicrobiana multifatorial, que resulta em um processo inflamatório crônico o qual afeta os tecidos de proteção e sustentação dos dentes, que pode resultar na perda do elemento dentário. A introdução do uso de antimicrobianos como adjuvantes a terapia mecânica torna-se uma opção terapêutica para melhorar a higiene oral. Produtos naturais têm sido utilizados cada vez mais para o controle químico do biofilme dentário. Dentre eles, destaca-se a própolis, que é um componente resinoso coletado pelas abelhas em diferentes partes das plantas, que apresenta atividade como um agente preventivo de cáries e no tratamento das doenças periodontais, em razão de sua ação bactericida, fúngica e anti-inflamatória. O objetivo desse estudo é verificar o efeito do uso da própolis no tratamento das doenças periodontais, abordando meios de utilização, vantagens e desvantagens da própolis na periodontia, através de uma revisão de literatura. Foram realizadas buscas nas bases de dados Scientific Eletronic Library Online (SciELO), Biblioteca Virtual em Saúde (BVS), US National libraryof Medicine National Institutes of Health (PubMed), Google Acadêmico, bem como artigos em bases de dados de instituições de ensino superior no Brasil. De acordo com os dados disponíveis na literatura, pode-se concluir que o uso da própolis como coadjuvantes ao tratamento mecânico periodontal em pacientes com doenças periodontais apresenta efeitos significativos positivos nos parâmetros clínicos periodontais e microbiológicos, visto que a própolis apresenta atividade anti-inflamatória e antimicrobiana.

Palavras-chave: Própolis; Gengivite; Periodontite; Terapia coadjuvante.

\begin{abstract}
Periodontal disease (PD) is defined as a multifactorial polymicrobial infection that results in a chronic inflammatory process that affects the protective and supportive tissues of the teeth, which can result in the loss of the tooth element. The introduction of the use of antimicrobials as an adjunct to mechanical therapy becomes a therapeutic option to improve oral hygiene. Natural products have been increasingly used for chemical control of dental biofilm. Among them, propolis stands out, which is a resinous component collected by bees from different parts of the plants, several studies prove the activity of propolis as a preventive agent for caries and in the treatment of periodontal diseases, in addition to having bactericidal, fungal and anti-inflammatory. The aim of this study is to verify the effect of using propolis in the treatment of periodontal diseases, addressing means of use, advantages and disadvantages of propolis in periodontics, through a literature review. Searches were performed in the Scientific Electronic Library Online (SciELO), Virtual Health Library (VHL), US National library of Medicine, National Institutes of Health (PubMed) databases, Academic Google, as well as articles in databases of higher education institutions in the Brazil. According to the data available in the literature, it can be concluded that the use of propolis as an adjunct to periodontal mechanical treatment in patients with periodontal diseases has significant positive effects on clinical periodontal and microbiological parameters, since propolis has anti-inflammatory and antimicrobial activity.
\end{abstract}

Keywords: Propolis: Gingivitis; Periodontitis; Adjunctive therapy.

\section{Resumen}

La enfermedad periodontal (EP) se define como una infección polimicrobiana multifactorial que resulta en un proceso inflamatorio crónico que afecta los tejidos protectores y de soporte de los dientes, lo que puede resultar en la pérdida del elemento dental. La introducción del uso de antimicrobianos como complemento de la terapia mecánica se 
convierte en una opción terapéutica para mejorar la higiene bucal. Los productos naturales se han utilizado cada vez más para el control químico de la biopelícula dental. Entre ellos, se destaca el propóleo, que es un componente resinoso recolectado por las abejas de diferentes partes de las plantas, varios estudios prueban la actividad del propóleo como agente preventivo de caries y en el tratamiento de enfermedades periodontales, además de tener propiedades bactericidas, fúngicas y antiinflamatorio. El objetivo de este estudio es verificar el efecto del uso del propóleo en el tratamiento de las enfermedades periodontales, abordando formas de uso, ventajas y desventajas del propóleo en periodoncia, a través de una revisión de la literatura. Las búsquedas se realizaron en la Scientific Electronic Library Online (SciELO), Virtual Health Library (VHL), US National Library of Medicine, National Institutes of Health (PubMed) bases de datos, Academic Google, así como artículos en bases de datos de instituciones de educación superior en el Brasil. De acuerdo con los datos disponibles en la literatura, se puede concluir que el uso de propóleo como coadyuvante al tratamiento mecánico periodontal en pacientes con enfermedades periodontales tiene efectos positivos significativos sobre los parámetros clínicos periodontales y microbiológicos, ya que el propóleo tiene actividad antiinflamatoria y antimicrobiana.

Palabras clave: Propóleos; Gingivitis; Periodontitis; Terapia complementaria.

\section{Introdução}

A doença periodontal (DP) é definida como uma infecção de natureza polimicrobiana multifatorial, que resulta em um processo inflamatório crônico o qual afeta os tecidos de proteção e sustentação dos dentes de indivíduos susceptíveis, o que pode resultar na perda do elemento dentário (Page et al., 1997). A mesma inicia-se quando o equilíbrio entre a microbiota e o hospedeiro é rompido e resulta em um crescimento desordenado de algumas bactérias patogênicas, que pode provocar um desequilíbrio no microambiente periodontal devido à produção de fatores de virulência que induzem inflamação e destruição dos tecidos periodontais. Com um novo ambiente patogênico e uma alteração da resposta imunológica do hospedeiro, a disbiose é então estabelecida (Page et al., 1997; Lamont \& Hajishegallis, 2015; Hajishengallis \& Lamount, 2012; Kinane et al., 2017).

O tratamento das DPs concentra-se na supressão da microbiota patogênica periodontal, modulando a resposta do hospedeiro e promovendo uma cicatrização dos tecidos, fornecendo um ambiente favorável para o reestabelecimento de uma microbiota compatível com a saúde periodontal através raspagem e alisamento radicular (Haffajee et al., 2009). O sucesso da terapia periodontal, independente do protocolo terapêutico, só é obtido por meio de um controle mecânico adequado do biofilme dentário, entretanto a maioria dos indivíduos não realiza esse controle de placa eficiente (Slots, 2012), principalmente em algumas regiões de difícil acesso, como em bolsas profundas e áreas de furca. A introdução do uso de antimicrobianos como adjuvantes a terapia mecânica torna-se uma opção terapêutica para melhorar a higiene oral (Addy, 2008), reduzindo a microbiota patogênica, e dessa forma, promovendo ganhos clínicos relevantes (Meira et al., 2007).

Considerando os efeitos colaterais sistêmicos, o aumento disseminado da resistência antimicrobiana, o alto custo dos antibióticos de nova geração, produtos naturais têm sido utilizados cada vez mais utilizados para o controle químico do biofilme dentário (Teixeira, 2016; Assis, 2018). Dentre eles, destaca-se a própolis, por apresentar propriedades antiinflamatórias e antimicrobianas, sendo um potente inibidor da síntese de glucanas, além de reduzir o crescimento de estreptococos cariogênicos, como Streptococcus sobrinus, e de bactérias anaeróbicas como Porphyromonas gingivalis e Prevotella intermedia, considerados periodopatógenos (Daugsch, 2008).

A própolis é um componente resinoso coletado pelas abelhas em diferentes partes das plantas como folhas, cascas, talos, entre outras, especialmente de espécies coníferas. As abelhas acrescentam enzimas salivares, cera e pólen ao extrato bruto, gerando o produto. Apresenta uma coloração dourado-escuro, substância essa que as abelhas após extraírem o composto a levam de volta para suas colônias, combinado com cera de abelha, e em seguida, a utilizam em suas colmeias como um agente selante e esterilizante para evitar pragas que possam atingi-las. (Geraldo, 2017).

Diversos estudos comprovam a atividade da própolis como agente preventivo de cáries dentais e no tratamento das doenças periodontais (De Luca et al., 2017; Yoshimasu et al., 2018), além de ter ação bactericida, fúngica e anti-inflamatória 
(Niedzielska et al., 2016). O efeito do extrato etanólico da própolis possui atividade antimicrobiana sobre diversos microrganismos orais no biofilme dentário, sendo comparado a clorexidina (Akca et al., 2016).

Diante da relevância da própolis no tratamento de doenças orais, o presente estudo, por meio de uma revisão de literatura, tem como objetivo verificar o efeito do uso da própolis como um coadjuvante no tratamento das doenças periodontais, abordando meios de utilização, vantagens e desvantagens da própolis vermelha na periodontia.

\section{Metodologia}

\subsection{Protocolo e Registro}

Este estudo foi submetido a Revista Research, Society and Development - ISSN 2525-3409, de acordo com as diretrizes de Itens de submissão da revista.

\subsection{Procura literária}

Para desenvolvimento desse trabalho, uma estratégia de busca foi realizada para identificar artigos que utilizaram própolis em pacientes com diagnóstico de doença periodontal como coadjuvante à terapia mecânico (Figura 1). Foram selecionados artigos das bases de dados: Scientific Eletronic Library Online (SciELO), Biblioteca Virtual em Saúde (BVS), US National library of Medicine National Institutes of Health (PubMed), Google Acadêmico, bem como artigos em bases de dados de instituições de ensino superior no Brasil, e revistas científicas foram utilizados para busca de artigos de acordo com os critérios de inclusão. As palavras-chave para a busca nas bases de dados foram: "Propolis"; "Gingivitis"; "Periodontitis"; "Adjunctive therapy"; "Red propolis"; "Green Propolis". Todos as palavras foram adaptadas para as diferentes bases de dados.

Figura 1. Fluxograma das bases de dados utilizados no estudo.

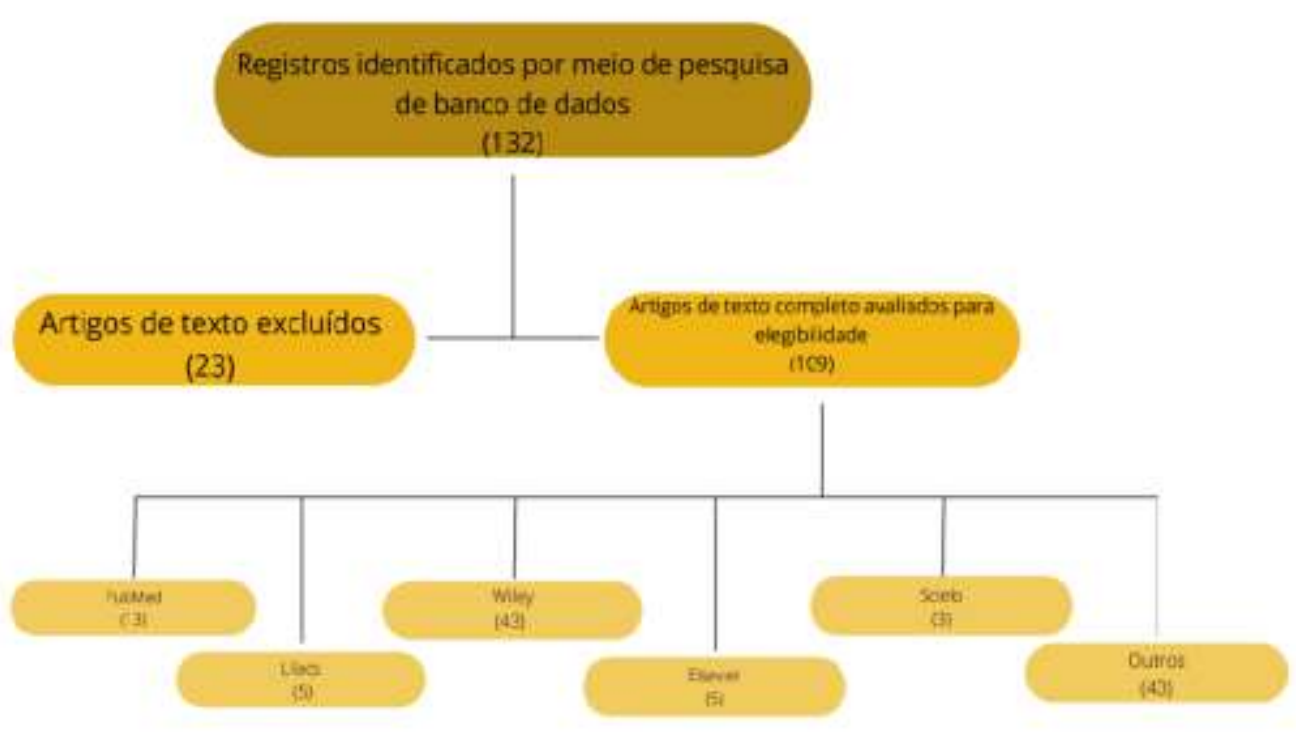

Fonte: Autores.

\subsection{Critérios de elegibilidade e processo de seleção}

A questão foco desta revisão foi "O uso da própolis como tratamento coadjuvante à doença periodontal". Foram utilizadas como critérios de inclusão: artigos e trabalhos publicados na língua portuguesa e inglesa no período de 1997 a 2021 , bem como estudos experimentais realizados em humanos, com o objetivo de realizar uma revisão de literatura voltada para o uso da própolis no controle do tratamento da doença periodontal (DP). Como critérios de exclusão, foram descartados da pesquisa estudos não disponíveis na íntegra. 


\section{Revisão de Literatura}

Considerada uma problemática de saúde mundial, a doença periodontal (DP) é uma das doenças inflamatórias crônicas humanas mais frequentes na população mundial e estima-se que entre 30-50\% dos adultos com 30 anos ou mais de idade sejam acometidos por esta doença (Albandar, 2002; Baelum \& Scheutz, 2002; Sheiham \& Netuveli, 2002; Dye, 2012). A mesma corresponde à segunda maior causa de perda dentária no mundo (Petersen \& Ogawa, 2005), assim como no Brasil, sendo a mais prevalente depois da cárie dentária (MS, 2011) e corresponde a segunda doença bucal de maior prevalência em humanos, já que $70 \%$ da população mundial apresenta um ou mais danos nos tecidos periodontais que incluem: gengiva, ligamento periodontal e osso alveolar (Oppermann et al., 2015).

Clinicamente, as DPs podem ser agrupadas em duas entidades distintas, as gengivites e periodontites conforme estabelecido pela nova classificação de doença periodontal proposta no 2017 World Workshop on the Classification of Periodontal and Periimplant Diseases and Conditions (Caton et al., 2018), levando-se em consideração a apresentação clínica, idade, níveis de gravidade, extensão, em relação à progressão e resposta terapêutica da doença, bem como fatores sistêmicos e locais que podem aumentar o risco (Maia et al., 2017). A gengivite caracteriza-se como uma inflamação superficial da gengiva, reversível, na qual o epitélio encontra-se íntegro, sem haver perda de inserção, apesar das alterações patológicas, com sinais clínicos de sangramento e edema. Sendo uma condição reversível e sem maiores consequências para o hospedeiro quando um adequado controle do biofilme dental é instituído (Newman et al., 1994; Kinane et al., 2017). Já a periodontite é uma doença resultante de uma disbiose significativa da microbiota subgengival, que ocasiona um quadro inflamatório crônico com destruição do tecido periodontal de suporte. Existe um acúmulo de placa nos tecidos mais profundos, causando uma perda de inserção por destruição do tecido conjuntivo e reabsorção do óssea (Hajishengallis \& Lamont, 2012; Bartold \& Van Dyke, 2013; Kinane et al., 2017).

Colombo et al (2016) relatam que as DPs estão entre as doenças infecciosas orais mais comuns associados com a estabelecimento de um biofilme disbiótico patogênico que provoca uma resposta imune/inflamatória ao hospedeiro, ocasionando um desequilíbrio no microambiente periodontal devido à produção de fatores de virulência que induzem uma inflamação e destruição dos tecidos periodontais. Além dos problemas provocados pelo impacto negativo desta doença na qualidade de vida oral, periodontopatógenos têm sido reportados como fatores de risco potenciais para diversas doenças sistêmicas, sendo o biofilme subgengival um reservatório de bactérias de importância clínica na cavidade oral (Espíndola et al., 2021; Espíndola et al., 2021).

Para se obter sucesso na terapia periodontal, o controle da placa faz-se essencial. Em diversos estudos ficaram estabelecidos o papel fundamental da higiene oral (do Amaral et al., 2006; Barbosa et al., Newman et al., 2012). Através dos avanços científicos e tecnológicos, como a biologia molecular, tem-se conseguido comprovar que a terapia básica periodontal e métodos de controle da placa parecem ter efeito benéfico na composição da microbiota subgengival (Ximenez - Fyvie et al., 2000; Haffajee et al., 2003; Carvalho et al., 2004). Entretanto, a maioria dos indivíduos não consegue remover de forma eficaz a placa, principalmente nas áreas interdentais (Cumming \& Loe, 1973). Além de fatores como destreza manual e rigor dos indivíduos, que podem influenciar o autocontrole do biofilme dentário (Frandsen, 1986; Wilson, 1987). Os resultados da limpeza mecânica forneceram a base para a implementação de conceitos de prevenção, mas, ao mesmo tempo, também sugerem a necessidade do desenvolvimento de agentes adjuvantes para o controle químico de placa (Albert-Kiszely et al., 2007).

Os experimentos clássicos de Löe et al., (1965) demonstraram que o acúmulo de placa durante 3 semanas resultou no desenvolvimento de gengivite generalizada. Do mesmo modo, após a remoção da placa reverteu-se a inflamação gengival. Vários estudos confirmam esses achados tanto em humanos como em animais experimentais (Lindhe et al., 1975; Payne, 1975; Page \& Schroeder, 1976; Moore et al., 1982; Brecx et al., 1987; Brecx et al., 1988). Procedimentos de higiene bucal também 
podem influenciar positivamente a ecologia microbiana nas diversas profundidades de bolsas periodontais (Siegrist \& Kornman, 1982; Dahle'n et al., 1992; Al-Yahfoufi et al., 1995).

Com a finalidade de minimizar o biofilme periodontal patogênico, a raspagem e o alisamento radicular (RAR) é instituída como tratamento básico de referência na terapia periodontal, que consiste na remoção do biofilme dentário, cálculo supragengival e subgengival, cemento e dentina contaminada (Newman \& Carranza, 2004). A RAR corresponde a terapêutica periodontal que apresenta seus efeitos clínicos bem documentados, sendo verificada a redução da inflamação, diminuição da profundidade de sondagem e do nível clínico de inserção (Morrison et al., 1980; Badersten et al., 1981; Lindhe et al., 1983; Pihlstrom et al., 1983; Ramfjord et al., 1987; Kaldahl et al., 1993; Haffajee et al.,1997; Carvalho et al., 2005; Colombo et al., 2005). Essas alterações clínicas estão associadas às alterações microbiológicas como a diminuição nos níveis de patógenos periodontais após a RAR (Slots, 1979; Pedrazzoli et al., 1991; Haffajee et al., 1997; Colombo et al., 2005). Apesar da grande eficácia da RAR como terapia básica periodontal, verificou-se que esta tem um efeito limitado sobre alguns patógenos (Haffajee et al., 1997; Cugini et al., 2000; Colombo et al., 2005). Isso pode ser devido à dificuldade em se eliminar esses patógenos em regiões de difícil acesso, como em sítios com bolsas periodontais profundas (Darby et al., 2005; Doungudomdacha et al., 2001) ou em defeitos de furca (Loos et al., 1988), bem como no interior de tecidos de células epiteliais (Colombo et al., 2007; Colombo et al., 2009). Além disso, vale salientar que os patógenos periodontais podem colonizar, além da bolsa periodontal, outros sítios intra-orais tais como a língua, amígdalas e membranas mucosas (Asikainen et al., 1991; Danser et al., 1994), podendo ocorrer a translocação intra-oral de patógenos de um sítio para outro. Assim, podese fazer o uso de agentes antimicrobianos como coadjuvantes ao controle mecânico de placa, bem como à terapia básica de RAR (DePaola et al., 1989; Lang et al., 1982; Overholser et al., 1980; Socransky \& Haffajee, 2002).

Com o objetivo de conseguir um controle de biofilme efetivo, diversos agentes químicos antimicrobianos podem ser utilizados como coadjuvantes à terapia mecânica, como o uso de antibióticos e antissépticos. No entanto, o uso dessas substâncias químicas apresenta efeitos colaterais como hipersensibilidade à composição da droga, problemas gástricos, resistência antimicrobiana, além da não colaboração do paciente na forma de administração do fármaco. E embora a descoberta do antibiótico, há 70 anos, tenha revolucionado a medicina, o aumento da resistência bacteriana aos antibióticos é um delicado assunto de intenso debate motivado por preocupações econômicas e políticas (Martino, 2018). Diversos produtos naturais vêm sendo estudados como coadjuvantes a terapia mecânica, como a própolis na área da periodontia (Geraldo, 2017).

A própolis é o nome genérico de uma complexa mistura resinosa coletada pelas abelhas dos botões e exsudatos de várias plantas. Após a coleta, esse material é enriquecido com saliva e secreções contendo enzimas e utilizado na construção, adaptação e proteção de colmeias (Palombo, 2011). Sua composição química inclui flavonóides, aminoácidos, polissacarídeos, hidrocarbonetos, ácidos graxos e outros (Lustosa et al., 2008). A mesma apresenta propriedades anti-inflamatórias, antissépticas e cicatrizantes sobre o tecido biológico, sendo uma excelente escolha como adjuvante ao tratamento das DPs, que pode ser usada em formas de soluções puras ou enxaguantes bucais, pomadas e dentifrícios. Além disso, não apresenta efeitos colaterais maiores, além de baixo custo (Francisco, 2010).

Os elementos farmacologicamente ativos de grande valia na própolis são os flavonóides, ácidos fenólicos, aromáticos e o ácido cafeico. Ainda possui ferro, zinco, proteínas, aminoácidos, vitaminas e minerais. (Galvão \& Galvão, 2003). Os flavonóides concentrados da própolis são poderosos antioxidantes, ou seja, apresentam a capacidade de destruir os radicais livres e assim proteger os lipídeos e outros compostos, tais como a vitamina C, de serem oxidados ou destruídos. É provável que os radicais livres ativos, juntamente com outros fatores sejam responsáveis pelo envelhecimento e degradação celular em condições tais como doenças cardiovasculares, artrite, câncer, diabetes, doença de Parkinson e doença de Alzheimer (Geraldo, 2017).

Em seu estudo, Galvão e Galvão (2003) observaram que a própolis atuava na inibição da síntese de prostaglandinas, 
ativando a glândula timo, auxiliando dessa forma o sistema imunológico, o que propicia a atividade fagocitária, estímulo da imunidade celular e aumento dos efeitos de cicatrização nos tecidos epiteliais. Cada vez mais estudos sobre as aplicações da própolis têm aumentado devido às suas propriedades terapêuticas e biológicas, sendo a mesma utilizada no tratamento de diversas infecções orais, como no tratamento de úlceras aftosas, candidíase, gengivite, periodontite e, até mesmo, pulpites (Samet et al.; Santos et al., 2005; Pereira et al., 2011; Coutinho, 2012; Giammarinaro et al., 2018).

Além disso, a ação cicatrizante da própolis foi relatada em um estudo realizado por Pensin et al., (2009), onde fora realizado o uso de uma pomada de própolis orabase para o tratamento de úlceras aftosas recorrentes utilizadas nos indivíduos que já haviam sido submetidos a diferentes tipos de tratamentos, e sem resultados satisfatórios. De acordo com os resultados obtidos nesse estudo, a pomada de própolis orabase acelerou o processo de cicatrização das úlceras recorrentes. Também foi observado uma significativa redução na dor descrita pelos pacientes, e um prolongamento no tempo entre o surgimento das lesões.

A ação antibacteriana da própolis frente a patógenos orais anaeróbicos foi reportada por Gebaraa et al., (2002), sendo demonstrado ação sobre Peptostreptococcus anaerobius, Lactobacillus acidophilus, Actinomyces naeslundii, Prevotella oralis, Prevotella melaninogenica, Porphyromonas gingivalis, Fusobacterium nucleatum e Veillonella parvula. Estudos realizados com modelos animais também observaram uma resposta à administração sistêmica da própolis. Ota, (1998) observaram a presença de atividade antibacteriana da própolis, in vitro, sobre S. mutans e Lactobacilllus spp., além de demonstrar capacidade de inibição do crescimento de uma série de microrganismos bacterianos encontrados na cárie dentária. Corroborando com os resultados obtidos em um recente estudo in vitro frente a atividade da própolis brasileira e europeia contra microrganismos orais no biofilme, sem que foi observada atividades antimicrobianas e anti-biofilme, sugerindo ser uma substância potencial como coadjuvantes nos produtos de higiene bucal (Stähi et al., 2021) Já Toker et al., (2008), observaram em seu estudo uma resposta à administração sistêmica da própolis na periodontite experimental em ratos, sendo reportado uma redução significativa na perda óssea associada à periodontite quando administrado de forma sistêmica, impedindo desta forma a perda óssea alveolar nos ratos.

Já em relação a sua utilização na área da periodontia, diversos estudos demonstram um efeito benéfico frente aos parâmetros periodontais no controle das doenças periodontais associados à terapia de RAR (Figura 1). Foi observado no estudo realizado por Coutinho (2012) eficácia clínica e microbiológica do extrato de própolis como irrigante subgengival no tratamento de periodontite, sendo observado consideravelmente melhoras no uso do extrato de própolis como adjuvante à terapia mecânica em comparação a RAR de forma isolada, corroborando com os resultados obtidos por Sanghani et al., (2014), em que foi observado uma redução significativa dos parâmetros periodontais sobre a eficácia da própolis administrado localmente. Tais achados podem estar relacionados às propriedades antibacterianas e anti-inflamatórias da própolis. Nakao e colaboradores avaliaram o uso tópico da própolis adjuvante a terapia mecânica em pacientes com periodontite estágio II e III por meio de um estudo clínico randomizado, controlado, duplo-cego e foram reportados efeitos benéficos em sua utilização, verificando uma redução nos níveis de $P$. gingivalis, bem como dos parâmetros clínicos periodontais, como a profundidade sondagem e nível de inserção clínica (Nakao et al., 2020). Em um estudo in vitro realizado por Figueiredo et al., (2020) com a finalidade de avaliar a eficácia da própolis vermelha do Brasil (BRP), quanto a amoxicilina no controle do complexo vermelho, foi realizado com a utilização de culturas de biofilmes mistos contendo 31 espécies associadas com saúde e doença periodontal cultivadas por seis dias, onde os biofilmes maduros foram tratados no período de 24 horas com o extrato da BRP em diferentes concentrações, amoxicilina ou veículo (controle negativo). Sendo demonstrada atividades metabólicas dos biofilmes tratados com a BRP uma redução em 56\% e 57\%, respectivamente, em comparação com a redução de $65 \%$ obtida com amoxicilina, além de proporções mais baixas de espécies dos complexos periodontais vermelho, verde e amarelo. 
Research, Society and Development, v. 10, n. 17, e182101724341, 2021

(CC BY 4.0) | ISSN 2525-3409 | DOI: http://dx.doi.org/10.33448/rsd-v10i17.24341

Tabela 1. Estudos clínicos que utilizaram a própolis como coadjuvante à terapia periodontal.

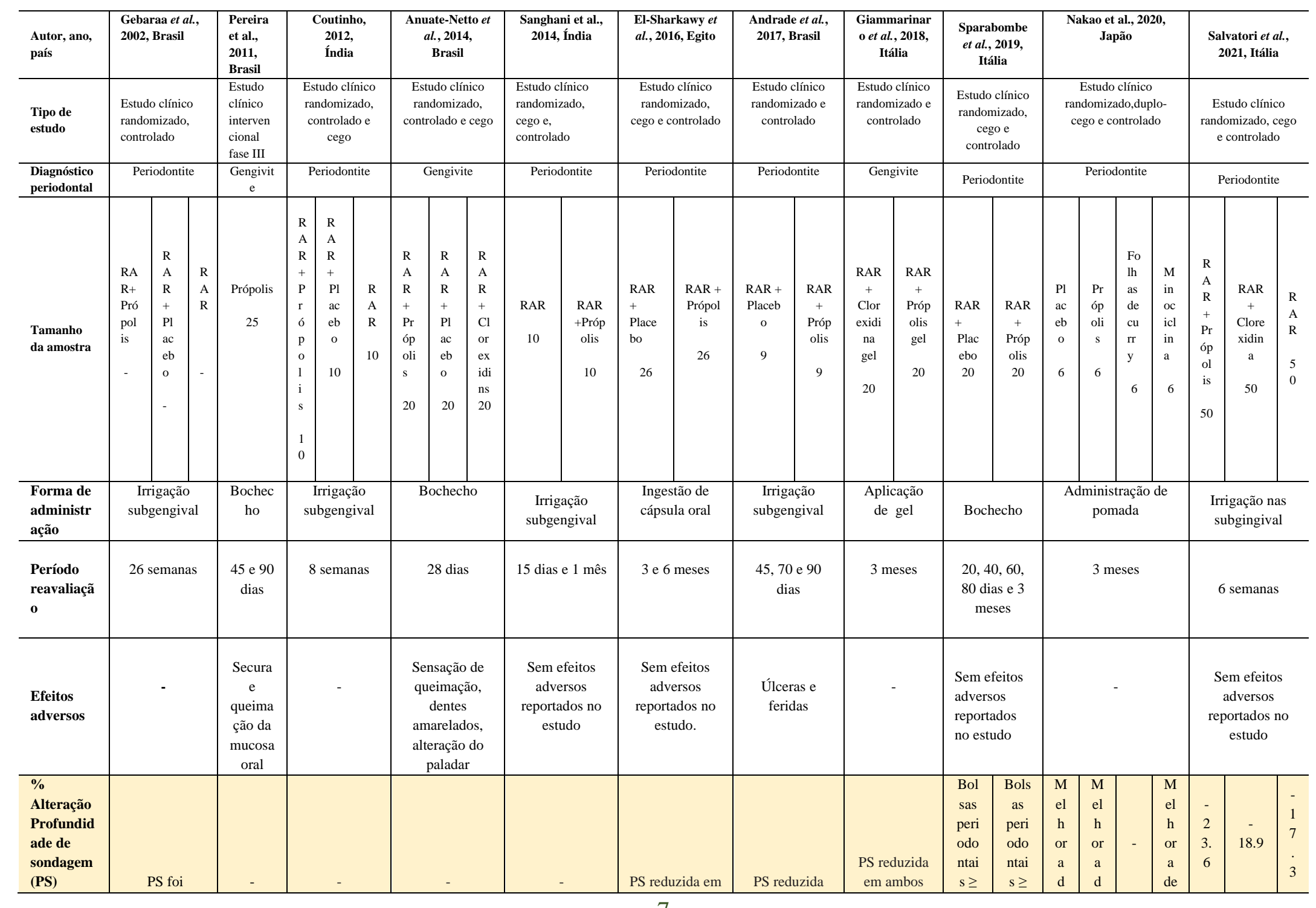


Research, Society and Development, v. 10, n. 17, e182101724341, 2021 (CC BY 4.0) | ISSN 2525-3409 | DOI: http://dx.doi.org/10.33448/rsd-v10i17.24341

\begin{tabular}{|c|c|c|c|c|c|c|c|c|c|c|c|c|c|c|c|c|c|c|c|}
\hline & $\begin{array}{c}\text { significativam } \\
\text { ente menor no } \\
\text { grupo da } \\
\text { própolis em } \\
\text { comparação } \\
\text { ao placebo e } \\
\text { RAR } \\
\text { isoladamente. }\end{array}$ & & & & & & & $\begin{array}{c}\text { ambos os } \\
\text { grupos após } 6 \\
\text { meses, sendo } \\
\text { essa redução } \\
\text { maior no grupo } \\
\text { da própolis } \\
\text { comparado ao } \\
\text { placebo. }\end{array}$ & $\begin{array}{c}\text { em ambos os } \\
\text { grupos após } 3 \\
\text { meses, sendo } \\
\text { essa redução } \\
\text { maior no } \\
\text { grupo da } \\
\text { própolis } \\
\text { comparado ao } \\
\text { placebo. }\end{array}$ & $\begin{array}{c}\text { os grupos. } \\
\text { No baseline } \\
\text { a \% PS + } \\
\text { DP o grupo } \\
\text { própolis de } \\
2.90 \pm 0.17 \\
\mathrm{~mm}, 1 \text { mês } \\
\text { após } \\
2.50 \pm 0.20 \\
\mathrm{~mm} \text { e aos } 3 \\
\text { meses de } \\
2.49 \pm 0.11 \\
\mathrm{~mm} .\end{array}$ & $\begin{array}{c}5 \\
\text { mm } \\
\text { no } \\
\text { base } \\
\text { line } \\
\text { de } \\
2.36 \\
\pm \\
3.21 \\
\mathrm{e} \\
\text { apó } \\
\text { so } \\
\text { trata } \\
\text { men } \\
\text { to } \\
\text { de } \\
1.37 \\
\pm \\
2.90\end{array}$ & $\begin{array}{c}5 \\
\text { mm } \\
\text { no } \\
\text { base } \\
\text { line } \\
\text { de } \\
8.23 \\
\pm \\
14,4 \\
2 \mathrm{e} \\
\text { após } \\
\text { o } \\
\text { trata } \\
\text { men } \\
\text { to } \\
\text { de } \\
1.12 \\
\pm \\
1.79\end{array}$ & \begin{tabular}{l|}
$\mathrm{e}$ \\
0. \\
3 \\
3 \\
\pm \\
0. \\
8 \\
2
\end{tabular} & $\begin{array}{l}\mathrm{e} \\
1 . \\
8 \\
3 \\
\pm \\
1 . \\
1 \\
7\end{array}$ & & \begin{tabular}{l|}
1. \\
5 \\
0 \\
\pm \\
1. \\
0 \\
5
\end{tabular} & & & \\
\hline $\begin{array}{l}\% \\
\text { Alteracãao } \\
\text { Nível de } \\
\text { inserção } \\
\text { clínica } \\
\text { (NIC) }\end{array}$ & $\begin{array}{c}\text { Não foram } \\
\text { observadas } \\
\text { diferenças } \\
\text { significativas } \\
\text { entre os } \\
\text { grupos } \\
\text { clínicos } \\
\text { testados. }\end{array}$ & - & - & & - & & - & $\begin{array}{l}\text { Ganho de } \\
\text { inserção após } 6 \\
\text { meses em } \\
\text { ambos os } \\
\text { grupos }\end{array}$ & - & - & $\begin{array}{c}\text { NIC } \\
\geq 4 \\
\text { mm } \\
\text { no } \\
\text { base } \\
\text { line } \\
\text { de } \\
33.4 \\
0 \pm \\
16.2 \\
8 \mathrm{e} \\
\text { apó } \\
\mathrm{so} \\
\text { trata } \\
\text { men } \\
\text { to } \\
\text { de } \\
27.3 \\
0 \pm \\
17.3 \\
9 .\end{array}$ & $\begin{array}{c}\text { NIC } \\
\geq 4 \\
\mathrm{~mm} \\
\text { no } \\
\text { base } \\
\text { line } \\
\mathrm{de} \\
43.2 \\
5 \pm \\
19.6 \\
5 \mathrm{e} \\
\text { após } \\
\text { o } \\
\text { trata } \\
\text { men } \\
\text { to } \\
\text { de } \\
29.1 \\
7 \pm \\
17.6 \\
6 .\end{array}$ & $\begin{array}{c}\mathrm{M} \\
\mathrm{el} \\
\mathrm{h} \\
\text { or } \\
\mathrm{a} \\
\mathrm{d} \\
\mathrm{e} \\
0 . \\
3 \\
3 \\
\pm \\
0 . \\
8 \\
2\end{array}$ & $\begin{array}{c}\mathrm{M} \\
\mathrm{el} \\
\mathrm{h} \\
\mathrm{or} \\
\mathrm{a} \\
\mathrm{d} \\
\mathrm{e} \\
1 . \\
6 \\
7 \\
\pm \\
1 . \\
2 \\
2\end{array}$ & $\begin{array}{c}\text { M } \\
\text { el } \\
\mathrm{h} \\
\text { or } \\
\mathrm{a} \\
\mathrm{d} \\
\mathrm{e} \\
0 . \\
2 \\
\pm \\
0 . \\
8 \\
4\end{array}$ & \begin{tabular}{c|} 
M \\
el \\
h \\
or \\
a \\
de \\
1. \\
3 \\
3 \\
\pm \\
1. \\
6 \\
2 \\
\end{tabular} & $\begin{array}{l}- \\
2 \\
1 . \\
2\end{array}$ & $\begin{array}{c}- \\
16.7\end{array}$ & $\begin{array}{l}- \\
1 \\
4\end{array}$ \\
\hline $\begin{array}{l}\% \\
\text { Alteracãao } \\
\text { Índice de } \\
\text { Placa (IP) }\end{array}$ & $\begin{array}{l}\text { Não foram } \\
\text { observados }\end{array}$ & $\begin{array}{l}\text { Reduçã } \\
\text { o em } \\
26 \% \text { no } \\
\text { IP aos } \\
45 \text { dias, }\end{array}$ & & \begin{tabular}{c|} 
P \\
S \\
ba \\
se \\
li \\
ne
\end{tabular} & \begin{tabular}{c|} 
P \\
S \\
ba \\
se \\
li \\
ne
\end{tabular} & $\begin{array}{c}\text { P } \\
\text { S } \\
\text { ba } \\
\text { se } \\
\text { li } \\
\text { ne }\end{array}$ & $\begin{array}{l}\text { Ambos os } \\
\text { grupos } \\
\text { mostraram } \\
\text { redução } \\
\text { estatisticament } \\
\text { e significativa }\end{array}$ & $\begin{array}{c}\text { Em ambos os } \\
\text { grupos foram } \\
\text { observadas }\end{array}$ & $\begin{array}{c}\text { Ambos os } \\
\text { grupos } \\
\text { apresentaram } \\
\text { melhora }\end{array}$ & $\begin{array}{c}\text { Foi } \\
\text { observada } \\
\text { redução do } \\
\text { IP em } \\
\text { ambos os } \\
\text { grupos, }\end{array}$ & $\begin{array}{c}\text { IP } \\
\text { no } \\
\text { base } \\
\text { line } \\
\text { de } \\
44.2\end{array}$ & $\begin{array}{c}\text { IP } \\
\text { no } \\
\text { base } \\
\text { line } \\
\text { de } \\
44.7\end{array}$ & & ambos & os gru & & $\begin{array}{l}- \\
5 \\
1 . \\
3\end{array}$ & $\begin{array}{c}- \\
43.0\end{array}$ & $\begin{array}{l}-5 \\
5\end{array}$ \\
\hline
\end{tabular}


Research, Society and Development, v. 10, n. 17, e182101724341, 2021 (CC BY 4.0) | ISSN 2525-3409 | DOI: http://dx.doi.org/10.33448/rsd-v10i17.24341

\begin{tabular}{|c|c|c|c|c|c|c|c|c|c|c|c|c|c|c|c|c|}
\hline & $\begin{array}{l}\text { diferenças } \\
\text { significativas } \\
\text { entre os } \\
\text { grupos clínico } \\
\text { testados. }\end{array}$ & $\begin{array}{l}\text { entreta } \\
\text { nto não } \\
\text { foi } \\
\text { observa } \\
\text { da } \\
\text { diferen } \\
\text { ça } \\
\text { signific } \\
\text { ativa } \\
\text { aos } 90 \\
\text { dias. }\end{array}$ & - & \begin{tabular}{c|} 
de \\
1. \\
0 \\
$(0$ \\
.5 \\
a \\
e \\
ap \\
ós \\
28 \\
di \\
as \\
de \\
0. \\
5 \\
0 \\
.5 \\
)
\end{tabular} & $\begin{array}{l}\text { de } \\
0 . \\
9 \\
(0 \\
.4 \\
\text { ee } \\
\text { ap } \\
\text { os } \\
28 \\
\text { di } \\
\text { as } \\
\text { de } \\
0 . \\
7 \\
(0 \\
4 \\
)\end{array}$ & $\begin{array}{l}\mathrm{de} \\
1 . \\
1 \\
(0 \\
.5 \\
) \mathrm{e} \\
\text { ap } \\
\text { os } \\
28 \\
\mathrm{di} \\
\text { as } \\
\mathrm{de} \\
0 . \\
9 \\
(0 \\
.6 \\
)\end{array}$ & $\begin{array}{l}\text { em relação aos } \\
\text { parâmetros } \\
\text { clínicos. }\end{array}$ & $\begin{array}{l}\text { redução no } \\
\text { índice de placa } \\
\text { (p>0.05), } \\
\text { sendo o ganho } \\
\text { de inserção } \\
\text { clínica maior } \\
\text { no grupo da } \\
\text { própolis } \\
\text { comparado ao } \\
\text { placebo } \\
(\mathrm{p}<0.05) .\end{array}$ & $\begin{array}{c}\text { clínica no } \\
\text { padrão de } \\
\text { acúmulo de } \\
\text { placa, } \\
\text { considerado } \\
\text { como um } \\
\text { aumento na } \\
\text { o número de } \\
\text { faces dentais } \\
\text { sem placa } \\
\text { visível. }\end{array}$ & $\begin{array}{c}\text { sendo no } \\
\text { grupo da } \\
\text { própolis a } \\
\% \text { IP + DP } \\
\text { no baseline } \\
\text { de } 50 \pm 30 \%, \\
\text { em } 1 \text { e } 3 \\
\text { meses } 0 \% \text {; } \\
\text { enquanto } \\
\text { que no } \\
\text { grupo da } \\
\text { clorexidina } \\
\text { baseline de } \\
60 \pm 46 \%, 1 \\
\text { mês } \\
34 \pm 57 \% \text { e } \\
\text { aos } 3 \text { meses } \\
\text { de } \\
0.01 \pm 0.01 \% .\end{array}$ & $\begin{array}{c}1 \pm \\
16.0 \\
4 \mathrm{e} \\
\text { apó } \\
\text { so } \\
\text { trata } \\
\text { men } \\
\text { to } \\
\text { de } \\
29.7 \\
0 \pm \\
14.3 \\
8 .\end{array}$ & $\begin{array}{c}0 \pm \\
6.36 \\
\text { e } \\
\text { após } \\
\text { o } \\
\text { trata } \\
\text { men } \\
\text { to } \\
\text { de } \\
17.6 \\
4 \pm \\
5.59\end{array}$ & $\begin{array}{c}\text { foram observadas } \\
\text { redução no índice de } \\
\text { placa }\end{array}$ & & & \\
\hline $\begin{array}{l}\% \\
\text { Alteração } \\
\text { Sangrame } \\
\text { nto } \\
\text { gengival } \\
\text { (IG) }\end{array}$ & $\begin{array}{l}\text { Redução do } \\
\text { IG foram } \\
\text { maiores nos } \\
\text { grupo } \\
\text { própolis e } \\
\text { etanol } \\
\text { comparada à } \\
\text { RAR. }\end{array}$ & $\begin{array}{c}\text { Reduçã } \\
\text { o em } \\
40 \% \text { no } \\
\text { IG aos } \\
45 \text { dias. } \\
\text { Aos } 90 \\
\text { dias } \\
\text { não foi } \\
\text { vista } \\
\text { redução } \\
\text { signific } \\
\text { ativa. }\end{array}$ & - & & - & & - & - & $\begin{array}{l}\text { Melhora } \\
\text { significativa } \\
\text { no IG. }\end{array}$ & $\begin{array}{l}\text { Em ambos os } \\
\text { grupos foram } \\
\text { observadas } \\
\text { redução no } \\
\text { índice de } \\
\text { sangramento } \\
\text { gengival } \\
\text { entre os } \\
\text { grupos } \\
\text { testados (p> } \\
0.05 \text { ). }\end{array}$ & $\begin{array}{l}\text { San } \\
\text { gra } \\
\text { men } \\
\text { to } \\
\text { base } \\
\text { line } \\
\text { de } \\
9.19 \\
\pm \\
6.23 \\
\text { e } \\
\text { apó } \\
\text { S o } \\
\text { trata } \\
\text { men } \\
\text { to } \\
\text { de } \\
3.85 \\
\pm \\
2.68\end{array}$ & $\begin{array}{l}\text { San } \\
\text { gra } \\
\text { men } \\
\text { to } \\
\text { no } \\
\text { base } \\
\text { line } \\
\text { de } \\
12.2 \\
3 \pm \\
9.49 \\
\mathrm{e} \\
\text { após } \\
\mathrm{o} \\
\text { trata } \\
\text { men } \\
\text { to } \\
\text { de } \\
1.63 \\
\pm \\
1.74\end{array}$ & $\begin{array}{l}\text { Em ambos os grupos } \\
\text { foram observadas } \\
\text { redução no IG }\end{array}$ & $\begin{array}{l}\mathrm{R} \\
\mathrm{e} \\
\mathrm{d} \\
\mathrm{u} \\
\mathrm{c} \\
\tilde{a} \\
\mathrm{o} \\
\mathrm{d} \\
\mathrm{e} \\
6 \\
1 . \\
4\end{array}$ & $\begin{array}{c}\text { Red } \\
\text { ução } \\
\text { de } \\
42.8\end{array}$ & $\begin{array}{l}\mathrm{R} \\
\mathrm{e} \\
\mathrm{d} \\
\mathrm{u} \\
\mathrm{c} \\
\tilde{a} \\
\mathrm{o} \\
\mathrm{d} \\
\mathrm{e} \\
3 \\
4\end{array}$ \\
\hline $\begin{array}{l}\text { Método } \\
\text { diganóstic } \\
\text { e amostra } \\
\text { biológica }\end{array}$ & $\begin{array}{c}\text { Cultura } \\
\text { Placa } \\
\text { subgengival }\end{array}$ & - & $\begin{array}{l}\text { Cultura } \\
\text { Placa } \\
\text { subgengival }\end{array}$ & & - & & - & - & - & $\begin{array}{c}\text { Teste } \\
\text { antioxidante } \\
\text { salivar } \\
\text { Saliva }\end{array}$ & & & $\begin{array}{l}\text { PCR em tempo real } \\
\text { Saliva e fluído } \\
\text { gengival crevicular }\end{array}$ & & - & \\
\hline $\begin{array}{l}\text { Correlaçã } \\
\text { o }\end{array}$ & Diminuição & & Diminuição & & & & & & & $\begin{array}{c}\text { Observado } \\
\text { após a }\end{array}$ & & & $\begin{array}{l}\text { Analisados a } \\
\text { frequência de } P \text {. }\end{array}$ & & - & \\
\hline
\end{tabular}


Research, Society and Development, v. 10, n. 17, e182101724341, 2021

(CC BY 4.0) | ISSN 2525-3409 | DOI: http://dx.doi.org/10.33448/rsd-v10i17.24341

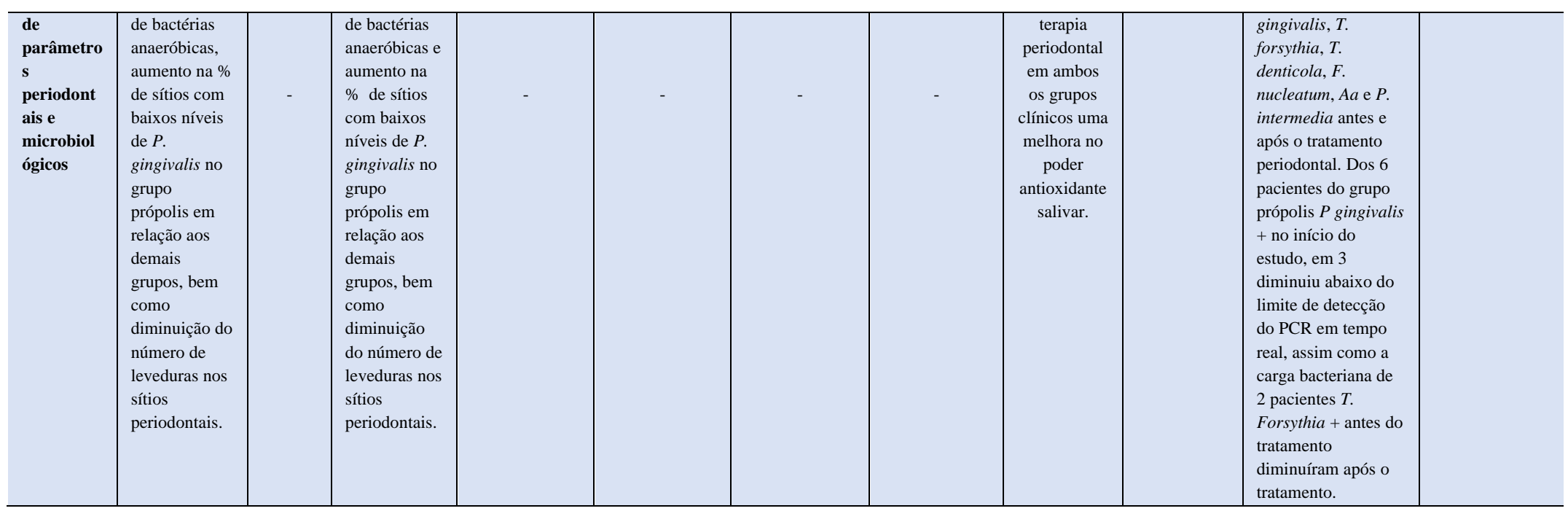

Legenda: -, não relatado; DP, desvio padrão; PS, profundidade de sondagem; NIC, nível de inserção clínico; IP, índice de placa; IG, índice gengival; RAR, raspagem e alisamento radicular; PCR, reação em cadeia de polimerase; M, masculino; F, mulher.

Fonte: Autores. 
Aral et al., (2015) analisaram a proteção óssea alveolar e os efeitos hipoglicêmicos do uso da própolis no tratamento de periodontite experimental relacionados ao Diabetes mellitus, em que ratos foram divididos em grupos distintos e feita a colocação de ligaduras para indução da periodontite e injeção de estreptozotocina para indução do diabetes. Os autores concluíram que a própolis reduziu significativamente os níveis de glicose no sangue em jejum em diabéticos. Além disso, a própolis comprovou ser benéfica como um tratamento auxiliar da periodontite associada ao diabetes e da periodontite sem diabetes.

Devido a sua estrutura complexa, a própolis não pode ser usada diretamente como matéria-prima. Diversos solventes podem ser utilizados para sua extração comercial, como os solventes a base de água, metanol, etanol, clorofórmio, diclorometano, éter e acetona. Muitos dos componentes bactericidas são solúveis em água ou álcool. Estes solventes removem o material inerte e preservam os compostos desejados (Geraldo, 2017). Mesmo sendo um produto natural, alguns efeitos adversos podem ser relatados, sendo as alergias, reações de hipersensibilidade e mucosite pelo uso contínuo as mais recorrentes (Frazão, 2017; Tanasiewicz et al., 2012; Pereira, 2014).

Por tratar-se de um novo produto de utilização odontológica, ainda não existe nenhuma fórmula comercial patenteada. Entretanto, por apresentar características anti-inflamatórias, antibacterianas, baixo custo e efeito adverso mínimo, cada vez mais a própolis vem estudada em pesquisas in vitro, em estudos com modelo animal e estudos clínicos em humanos, para que possa se conhecer seus benefícios e riscos acerca do produto, principalmente na área da periodontia.

\section{Discussão}

Nas últimas duas décadas houve um desenvolvimento limitado de produtos para cuidados bucais, isso deve-se principalmente por etapas químicas inconclusivas, escassez de ensaios clínicos ou estudos mal elaborados, falta de trabalho multidisciplinar e colaborativo, bem como de parceria e investimento da indústria neste setor. Assim, mais pesquisas devem ser necessárias nos campos de toxicologia e farmacologia clínica, de modo a preencher a lacuna entre o potencial in vitro e in vivo de novos agentes fitoterápicos e sua eficácia clínica e segurança em humanos. (Silva, 2019).

A própolis é uma substância natural de grande interesse para Odontologia, e tem se mostrado como eficaz coadjuvante no tratamento das doenças periodontais; apresentando propriedades anti-inflamatórias, antimicrobianas, antissépticas e cicatrizantes sobre o tecido biológico. Devido às suas propriedades, evidências sugerem que a própolis possa ativamente proteger contra doenças orais. (Ribeiro et al., 2015; Galvão \& Galvão, 2003; Pereira, 2014). Além de ser visto em estudo in vitro não apresenta citotoxicidade para as células do ligamento periodontal (Yuan et al., 2018).

Sendo a resistência antimicrobiana considerada um grave problema de saúde pública, listada como uma ameaça a vida humana, em que pelo menos 500.000 mil mortes resultaram de infecção decorrentes a resistência a antimicrobianos a cada ano em toda Europa e Estados Unidos (Van Boeckel et al., 2014), compostos e produtos naturais tem cada vez mais sendo estudado. Recentemente, diversos componentes químicos da própolis foram identificados, como os compostos fenólicos, flavonóides e terpenóides (Huang et al., 2014; Harvey et al., 2015). O efeito bactericida contra P. gingivalis está relacionado com a presença do artepelin C (ART C), ácido ursólico e baccarin (Yoshimasu et al., 2018). Esta última substância também apresenta ação anti-inflamatória, inibindo a produção de citocinas e eicosanóides, estimulando a produção de efetores reguladores como a interleucina-10 (Szliszka et al., 2013), já o ART C apresenta efeitos contra células do sistema imune, desempenhando também uma ação anti-inflamatória (Paulino et al., 2008).

Pensin et al., (2009) relatam que a pomada a base de própolis apresenta a capacidade de acelerar o processo de cicatrização nas úlceras recorrentes, além de proporcionar uma significativa redução na dor, e um prolongamento no tempo entre o surgimento das lesões. Além dessas características de acelerar o reparo na cicatrização e analgesia, Toker et al., (2008) observaram que após um período de 11 dias, a perda óssea alveolar foi significativamente menor em ratos no qual foi 
administrada de forma sistêmica ligaduras e própolis, além de que, o número dos osteoclastos desse grupo serem significativamente menores, sugerindo por meio dos achados histológicos que a própolis administrada na forma sistêmica apresenta a capacidade de prevenir a perda óssea alveolar.

Em um estudo que fez uso de uma solução irrigadora hidroalcóolica de própolis como adjuvante a terapia mecânica periodontal foi observado uma diminuição nas contagens totais de bactérias anaeróbias, diminuição dos níveis de $P$. gingivalis nos sítios, cerca de $45 \%$ a 79\%, além de redução nos parâmetros clínicos periodontais, como a profundidade de sondagem, demonstrando apresentar efeitos benéficos na sua aplicação (Gebaraa et al., 2003). Vale salientar que estudos adicionais se fazem necessários em relação a frequência de aplicação, incorporação da própolis para dispositivo de liberação lenta e uso dos compostos ativos purificados presentes na própolis, como a finalidade de obter resultados ainda melhores. Assim como Gebaraa et al., (2003), Coutinho (2012), Andrade et al., (2017) concluíram que a irrigação subgengival adicional com extrato de própolis durante o tratamento periodontal permite a obtenção de melhores resultados do que a RAR de forma isolada, ou irrigação com solução salina, sendo observado melhoria significativas nos parâmetros clínicos periodontais e microbiológicos.

Em um estudo acerca da eficácia do uso de enxaguante bucal contendo própolis verde brasileira no controle de biofilme e gengivite, pode-se comprovar a eficácia do enxaguante bucal com própolis no controle da placa bacteriana e gengivite, sugerindo que o mesmo possa ser utilizado com a finalidade terapêutica e preventiva das doenças periodontais (Pereira et al., 2011), além de apresentar eficácia na redução da inflamação gengival (Anauate-Netto et al., 2014), corroborando também com os resultados obtidos por de Figueiredo e colaboradores (2020), que realizaram um estudo in vitro utilizando a própolis vermelha do Brasil, que demonstrou ser tão eficaz quanto a amoxicilina ao ser utilizada como um coadjuvante na terapia periodontal, apresentando resultados diante da atividade metabólica do biofilme, além de não apresentar nenhuma alteração em relação ao crescimento benéfico de Actinomyces spp.. Também foi observado em um estudo clínico randomizado duplo cego um efeito positivo na utilização da própolis administrada via tópica adjuvante a terapia mecânica em pacientes com periodontite estágio II e III, sendo observado uma redução de $P$. gingivalis no fluído gengival crevicular e aumento de $F$. nucleatum e $A a$, utilizando o método de detecção PCR em tempo real, bem como uma redução na profundidade sondagem e nível de inserção clínica (Nakao et al., 2020). Essas diferenças entre os periopatógenos podem ser justificadas pela maior ou menor suscetibilidade de $P$. gingivalis, Aa e F. nucleatum, visto que a própolis apresenta atividade bactericida sobre a $P$. gingivalis de 8 a 16 vezes na concentração inibitória mínima (CIM) mais baixa que o Aa e o $F$. nucleatum (Yoshimasu et al., 2018). Assim como Coutinho relatou melhoras nos parâmetros periodontais, como sangramento à sondagem $\mathrm{e}$ profundidade de sondagem após a irrigação com o extrato de própolis em pacientes com periodontite (Coutinho, 2012), bem como foi demonstrado recentemente que o uso do enxaguatório que continha extrato de própolis em pacientes com periodontite foi eficaz na redução do sangramento à sondagem em comparação ao grupo placebo, entretanto não foram observados diferenças entre a profundidade de sondagem e nível de inserção clínica (Sparabombe et al., 2019).

\section{Considerações Finais}

De acordo com os dados disponíveis na literatura pode-se sugerir que o uso da própolis como uma alternativa coadjuvante ao tratamento mecânico periodontal em pacientes com doenças periodontais apresenta efeitos significativos positivos nos parâmetros clínicos periodontais e microbiológicos, visto que a própolis apresenta atividade anti-inflamatória e antimicrobiana. Novos estudos clínicos e microbiológicos sobre essa temática ainda se fazem necessários para maiores esclarecimentos em relação a sua concentração, forma de administração, efeitos colaterais e sua eficácia clínica em pacientes com DPs. 


\section{Referências}

Addy, M., (2008). Oral hygiene products: potential for harm to oral and systemic health? Periodontol 2000, 48, 54-65.

Akca A. E., Akca G., Topçu F. T., Macit E., \& Pikdöken L., \& Özgen I. Ş. (2016). The Comparative Evaluation of the Antimicrobial Effect of Propolis with Chlorhexidine against Oral Pathogens: An In Vitro Study. Biomed Res Int.,3627463.

Albadar, J. M., Muranga, M. B., \& Rams, T. E., (2002). Prevalência de periodontite agressiva em frequentadores de escolas em Uganda. Journal of Clinical Periodontology, 29 (9), 823-831.

Albert-Kiszely, A., Pjetursson, B. E., Salvi, G. E., Witt, J., Hzmilton A., Persson, G. R., \& Lang, N. P. (2007). Comparação dos efeitos do cloreto de cetilpiridínio com um enxágue bucal com óleo essencial na placa dentária e gengivite - um ensaio clínico controlado randomizado de seis meses. Journal of Clinical Periodontology, 34 (8), 658-667.

Al-Yahfoufi, Z., Mombelli, A., Wicki, A., \& Lang, N. P. (1995). The effect of plaque control in subjects with shallow pockets and high prevalence of periodontal pathogens. Journal of clinical periodontology, 22(1), 78-84. https://doi.org/10.1111/j.1600-051x.1995.tb01774.x

Anauate-Netto, C., Anido-Anido, A., Leegoy, H. R., Matsumoto, R., Alonso, R. C. B., Marcucci, M. C., \& Bretz, W. A. (2014). Ensaio clínico randomizado, duplo-cego, controlado por placebo sobre os efeitos da própolis e enxaguatórios bucais com clorexidina na gengivite. Ciência odontológica brasileira, 17 (1), 11 .

Andrade, D. P., Carvalho, I. C. S., Gadoi, B. H., Rosa, L. C. L., Barreto, L. M. R. C., \& Pallos, D. (2017). Irrigação subgengival com solução de extrato de própolis a $20 \%$ como coadjuvante do tratamento periodontal não cirúrgico: um estudo preliminar. J. Int. Acad. Periodontol, 19, $145-151$.

Aral, C. A., Kesim, S., Greenwell, H., Kara, M., Çetin, A., \& Yakan, B. (2015). Alveolar bone protective and hypoglycemic effects of systemic propolis treatment in experimental periodontitis and diabetes mellitus. Journal of medicinal food, 18(2), 195-201.

Asikainen, S., Lai, C. H., Alaluusua, S., \& Slots, J. (1991). Distribuição dos sorotipos de Actinobacillus actinomycetemcomitans na saúde e doença periodontal. Microbiologia oral e imunologia, 6 (2), 115-118.

Assis, M. A. D. S. (2018). Ação antimicrobiana e citotoxicidade de extratos aquoso e glicólico de própolis sobre bactérias anaeróbias de importância odontológica. https://repositorio.unesp.br/handle/11449/180563.

Badersten, A., Nilvéus, R., \& Egelberg, J. (1981). Efeito da terapia periodontal não cirúrgica: I. Periodontite moderadamente avançada. Journal of Clinical Periodontology, 8 (1), 57-72.

Baelum, V., \& Scheutz, F. (2002). Doenças periodontais na África. Periodontology 2000, 29 (1), 79-103.

Barbosa, V. L. S. D. A., Nóbrega, D. R. D. M., \& Cavalcanti, A. L. (2012). Estudo bibliométrico de pesquisas realizadas com fitoterápicos na Odontologia. Rev. bras. ciênc. saúde, 123-130.

Bartold, P. M., \& Van Dyke, T. E. (2013). Periodontite: uma interrupção da homeostase microbiana mediada pelo hospedeiro. Desaprender conceitos aprendidos. Periodontology 2000, 62 (1), 203-217.

Brecx, M. C., Fröhlicher, I., Gehr, P., \& Lang, N. P. (1988). Observações estereológicas na gengivite experimental de longo prazo no homem. Journal of Clinical Periodontology, 15 (10), 621-627.

Brecx, MC, Schlegel, K., Gehr, P., \& Lang, N. P. (1987). Comparação entre parâmetros histológicos e clínicos durante gengivite experimental humana. Journal of periodontal research, 22 (1), 50-57.

Carvalho, L. H., D'ávila, G. B, Leão, A., Haffajee, A. D., Socransky, S. S., \& Feres, M. (2004). Raspagem e alisamento radicular, metronidazol sistêmico e remoção de placa profissional no tratamento da periodontite crônica em uma população brasileira: I. Resultados clínicos. Journal of Clinical Periodontology , 31 (12), 1070-1076.

Carvalho, V. F. D., Fukuda, C. T., Okuda, O. S., Bernardo, C. C., \& Pannuti, C. M. (2005). Avaliação da cooperação aos retornos dos pacientes em manutenção periodontal. Periodontia, 5-9.

Caton, J. G., Armitage, G., Berglundh, T., Chapple, I. L., Jepsen, S., Kornman, K. S., \& Tonetti, M. S. (2018). Um novo esquema de classificação para doenças e condições periodontais e peri-implantar - Introdução e principais alterações da classificação de 1999. Journal of periodontology, 89, S1-S8.

Colombo, A. P. V., Magalhães, C. B., Hartenbach, F. A. R. R., do Souto, R. M., \& da Silva-Boghossian, C. M. (2016). Biofilme associado à doença periodontal: um reservatório para patógenos de importância médica. Patogese microbian , 94, 27-34.

Colombo, A. P. V., Boches, S. K., Cotton, S. L., Goodson, J. M., Kent, R., Haffajee, A. D., \& Paster, B. J., (2009). Comparações de perfis microbianos subgengivais de periodontite refratária, periodontite grave e saúde periodontal usando o microarray de identificação de micróbio oral humano. Journal of periodontology, 80 (9), 1421-1432. 
Colombo, A. P. V., Teles, R. P., Torres, M. C., Rosalém Jr, W., Mendes, M. C. S., Souto, R. M., \& de Uzeda, M. (2005). Efeitos da terapia mecânica não cirúrgica na microbiota subgengival de brasileiros com periodontite crônica não tratada: resultados de 9 meses. Journal of periodontology, 76 (5), 778 -784.

Colombo, A. V., Da Silva, C. M, Haffajee, A., \& Colombo, A. P. V. (2007). Identificação de espécies orais intracelulares em células epiteliais creviculares humanas de indivíduos com periodontite crônica por hibridização fluorescente in situ. Journal of periodontal research, 42 (3), $236-243$.

Coutinho A. (2012). Honeybee propolis extract in periodontal treatment. A clinical and microbiological study of propolis in periodontal treatment. Indian $J$ Dent Res., 23,294-99.

Cugini, M. A., Haffajee, A. D., Smith, C., Kent Jr, R. L., \& Socransky, S. S. (2000). O efeito da raspagem e alisamento radicular nos parâmetros clínicos e microbiológicos das doenças periodontais: resultados de 12 meses. Journal of Clinical Periodontology, 27 (1), $30-36$.

Cumming, B. R., \& Löe, H. (1973). Consistência da distribuição da placa em indivíduos sem instrução especial de cuidado domiciliar. Journal of Periodontal Research, 8 (1), 94-100.

Dahlen, G., Manji, F., Baelum, V., \& Fejerskov, O. (1992). Periodontopatógenos putativos em pessoas "doentes" e "não doentes" exibindo higiene oral deficiente. Journal of Clinical Periodontology, 19 (1), 35-42.

Danser, M. M., Van Winkelhoff, A. J., De Graaff, J., Loos, B. G., \& Van der Velden, U. (1994). Efeito de curto prazo da extração de boca inteira nos patógenos periodontais que colonizam as membranas mucosas orais. Journal of Clinical Periodontology, 21 (7), 484-489.

Daugsch, A., Moraes, CS, Fort, P., \& Park, YK (2008). Própolis vermelha brasileira - composição química e origem botânica. Medicina complementar e alternativa baseada em evidências, 5 (4), 435-441.

Darby, E. U. B., Angkasa, F., Duong, C., Ho, D., Legudi, S., Pham, K., \& Welsh, A. (2005). Fatores que influenciam o diagnóstico e o tratamento da doença periodontal por dentistas em Victoria. Revista odontológica autraliana, 50(1), 37-41.

De Figueiredo, K. A., da Silva, H. D. P., Miranda, S. L. F., Gonçalves, F. J. dos S., de Sousa, A. P., de Figueiredo, L. C., Feres, M., et al. (2020). A própolis vermelha brasileira é tão eficaz quanto a amoxicilina no controle do complexo vermelho de biofilme subgengival maduro multiespécies in vitro. Antibiotics, 9 (8), 432 .

De Luca M.P., Freires I. A., Gala-García A., Santos V. R., Vale M. P., Alencar S. M., et al. (2017). The anti-caries activity and toxicity of an experimental propolis-containing varnish. Braz Oral Res., 5,31:e45.

De Paola, L. G., Overholser, C. D., Meiller, T. F., Minah, G. E., \& Niehaus, C. (1989). Inibição quimioterápica da placa dentária supragengival e do desenvolvimento de gengivite. Journal of Clinical Periodontology, 16 (5), 311-315.

Do Amaral, R. C., Gomes, R. T., Rocha, W. M. S., Lemos, S., Abreu, R., \& Santos, V. R. (2006). Tratamento da periodontite com gel de própolis verde brasileira. Pharmacologyonline, 3, 336-341.

Doungudomdacha, S., Rawlinson, A., Walsh, T. F., \& Douglas, C. W. E.U. (2001). Efeito do tratamento periodontal não cirúrgico nos parâmetros clínicos e no número de Porphyromonas gingivalis, Pavotella intermedia e Actinobacillus actinomycetemcomitans em locais de periodontite adulta. Journal of Clinical Periodontology, 28(5), 437-445.

Dye, B. A. (2012). Epidemiologia da doença periodontal global. Periodontology 2000, 58 (1), 10-25.

Espíndola, L. C. P., do Nascimento, M. V. M. R., do Souto, R. M., Colombo, A. P. V. (2021). Antimicrobial susceptibility and virulence of Enterococcus spp. isolated from periodontitis-associated subgingival biofilm. J Periodontol, 92(11),1588-1600.

Espíndola, L. C. P., Picão, R. C., Mançano, S. M. C. N., Martins do Souto, R., \& Colombo, A. P. V. (2021). Prevalence and antimicrobial susceptibility of Gram-negative bacilli in subgingival biofilm associated with periodontal diseases. J Periodontol. doi: 10.1002/JPER.20-0829.

Francisco, K. S. F. (2010). Fitoterapia: uma opção para o tratamento odontológico. Revista saúde, 4(1), 18-24

Frandsen, E. V., Theilade., E., Ellegaard, B., \& Kilian, M. (1986). Proporções e identidade de bactérias degradadoras de IgA1 em bolsas periodontais de pacientes com periodontite juvenil e rapidamente progressiva. Journal of periodontal research, 21 (6), 613-623.

Frazão, M. A. D. S. M. F. (2017). O uso de própolis na cavidade oral: revisão bibliográfica (Doctoral dissertation).

Galvão, J., \& Galvão, V. G. (2003). O uso da própolis em periodontia. Revista Brasileira de Pesquisa em Saúde/Brazilian Journal of Health Research.

Gebaraa, E. C., Pustiglioni, A. N., De Lima, L. A., \& Mayer, M. P. (2003). Propolis extract as an adjuvant to periodontal treatment. Oral Health Prev Dent, $1(1), 29-35$

Geraldo de, M. O. - O uso do propolis na peridontia. Artigo, 2017. <http://repositorio.saolucas.edu.br:8080/xmlui/bitstream/handle/123456 789/2000/Mahara\%20de\%20Oliveira\%20Geraldo\%20-\%20O\%20uso\%20da\%20pr\%C3\%B3polis\%20na\%20periodontia.pdf?sequence=1\&isAllowed=y. 
Giammarinaro, E., Marconcini, S., Genovesi, A., Poli, G., Lorenzi, C., \& Covani, U. (2018). Propolis as an adjuvant to non-surgical periodontal treatment: A clinical study with salivary antioxidant capacity assessment. Minerva Stomatol, 67, 183-188.

Haffajee, A. D., Cugini, M. A., Dibart, S., Smith, C., Kent Jr, R. L., \& Socransky, S. S. (1997). O efeito do SRP nos parâmetros clínicos e microbiológicos das doenças periodontais. Journal of Clinical Periodontology, 24 (5), 324-334.

Haffajee, A. D., Roberts, C., Murray, L., Veiga, N., Martin, L., Teles, R. P., \& Socransky, S. S. (2009). Efeito de enxaguatórios bucais à base de ervas, óleo essencial e clorexidina na composição da microbiota subgengival e nos parâmetros clínicos periodontais. Journal of Clinical Dentistry, 20 (7), 211.

Haffajee, A. D., Socransky, S. S., \& Gunsolly, J. C. (2003). Terapia periodontal antiinfecciosa sistêmica. Uma revisão sistemática. Annals of Periodontology, 8 (1), 115-181.

Hajishengallis, G., \& Lamont, R. J. (2012). Além do complexo vermelho e em mais complexidade: o modelo de sinergia polimicrobiana e disbiose (PSD) da etiologia da doença periodontal. Microbiologia oral molecular, 27 (6), 409-419.

Harvey, A. L., Edrada-Ebel, R., \& Quinn, R. J. (2015). The re-emergence of natural products for drug discovery in the genomics era. Nature reviews. Drug discovery, 14(2), 111-129.

H. Toker, F. Ozan, H. Ozer, H. Ozdemir, K. Eren, \& H. Yeler, (2008). "A morphometric and histopathologic assessment of the effects of própolis on alveolar bone loss in experimental periodontitis in rat", Journal of Periodontology 79(6), 1089-1094

Huang, S., Zhang, C. P., Wang, K., Li, G. Q, \& Hu, F. L. (2014). Avanços recentes na composição química da própolis. Molecules, 19 (12), $19610-19632$.

Kaldahl, W. B., Kalkwarf, K. L., \& Patil, K. D. (1993). Uma revisão de estudos longitudinais que compararam as terapias periodontais. Journal of periodontology, 64 (4), 243-253.

Kinane, D. F., Stathopoulou, P. G., Papapanou, P. N. (2017). Periodontal diseases. Nat Rev Dis Primers.,22(3),17-38.

Lamont, R. J., Hajishegallis, G. (2015). Polymicrobial synergy and dysbiosis in inflammatory disease. Trends Mol Med.,21(3),172-83.

Lang, N. P., Hotz, P., Graf, H., Geering, A. H., Saxer, U. P., Sturzenberger, O. P., \& Meckel, A. H. (1982). Efeitos de enxaguatórios bucais com clorexidina supervisionados em crianças: um ensaio clínico longitudinal. Journal of periodontal research, 17 (1), 101-111.

Lindhe, J., Haffaiee, A. D., \& Socransky, S. S. (1983). Progressão da doença periodontal em indivíduos adultos na ausência de terapia periodontal. Journal of Clinical Periodontology, 10 (4), 433-442.

Lindhe, J., Hamp, S. E., \& Löe, H. (1975). Doença periodontal induzida por placa em cães beagle: um estudo clínico, roentgenográfico e histométrico de 4 anos. Journal of periodontal research, 10 (5), 243-255.

Löe, H., Theilade, E., \& Jensen, S. B. (1965). Gengivite experimental no homem. The Journal of periodontology, 36 (3), $177-187$.

Loos, B., Claffey, N., \& Egelberg, J. (1988). Efeitos clínicos e microbiológicos do desbridamento radicular em bolsas de furca periodontal. Journal of Clinical Periodontology, 15 (7), 453-463.

Lustosa, S. R., Galindo, A. B., Nunes, L. C., Randau, K. P., \& Rolim Neto, P. J. (2008). Própolis: atualizações sobre a química e a farmacologia. Revista Brasileira de Farmacognosia, 18, 447-454.

Maia, M. B., Costa, G. S., \& da Silva, K. C. F. (2017). Associação entre diabetes mellitus e doença periodontal. Revista Intercâmbio, 10 , $181-197$.

Martino, V. J. M. R. (2018). Análise do uso de antimicrobianos locais no tratamento periodontal (Doctoral dissertation).

Meira, A. L. T., Todescan, S. M. C., Azoubel, E., Bittencourt, S., \& Azoubel, M. C. F. (2007). Use of local antimicrobials in periodontics: A critical approach. Periodontia, 17 (1): 92-98.

Moore, W. E., Holdeman, L. V., Smibert, R. M., Hash, D. E., Burmeister, J. A., \& Ranney, R. R. (1982). Bacteriologia da periodontite grave em humanos adultos jovens. Infecção e imunidade, 38 (3), 1137-1148.

Morrison, E. C., Ramfjord, S. P., \& Hill, R. W. (1980). Efeitos de curto prazo do tratamento periodontal não cirúrgico inicial (fase higiênica). Journal of Clinical Periodontology, 7 (3), 199-211.

Nakao, R., Senpuku, H., Ohnishi, M., Takai, H., \& Ogata, Y. (2020). Efeito da administração tópica de própolis na periodontite crônica. Odontology , 108 (4), 704-714.

Newman, M. T. H., \& Carranza, F. Periodontología clínica. (9a ed.), McGraw-Hill Interamericana; 2004.

Newman, M. G. Carranza Periodontia Clínica. Elsevier. 68-69; 111-110 p 
Newman, M. G., Kornman, K. S., \& Doherty, F. M. (1994). Uma avaliação multicêntrica de 6 meses da terapia adjuvante com fibras de tetraciclina usada em conjunto com raspagem e alisamento radicular em pacientes de manutenção: resultados clínicos. Journal of periodontology, 65 (7), $685-691$.

Niedzielska, I.; Puszczewicz, Z.; Mertas, A.; Niedzielski, D.; Rózanowski, B.; Baron, S.; Konopka, T.; Machorowska-Pieniazek, A.; Skucha-Nowak, M.; Tanasiewicz, M.; Paluch, J.; Markowski, J.; Orzechowska-Wylegaa, B.; Król, W. \& Morawiec, T. The influence of ethanolic extract of Brazilian green propolis gel on hygiene and oral microbiota in patients after mandible fractures. Biomed. Res. Int., 2016:9190814, 2016.

Oppermann, R. V., Haas, A. N., Rösing, C. K., \& Susin, C. (2015). Epidemiology of periodontal diseases in adults from Latin America. Periodontology 2000, 67(1), 13-33.

Oppermann, R. V., \& Rösing, C. K. (1997). Prevenção e tratamento das doenças periodontais. In ABOPREV promoçäo de saúde bucal (pp. 255-81).

Ota, C. (1998). Avaliação in vitro, da atividade antimicrobiana e ação anticariogênica da própolis em ratos. Tese de Doutorado. Universidade Estadual Paulista. Faculdade de Odontologia de São José dos Campos.

Overholser, C. D., Meiller, T. F., De Paola, L. G., Minah, G. E., \& Niehaus, C. (1990). Efeitos comparativos de 2 enxaguatórios bucais no desenvolvimento de placa dentária supragengival e gengivite. Journal of Clinical Periodontology, 17 (8), 575-579.

Page, R. C., Offenbacher, S., Schroeder, H. E., Seymour, G. J., Kornzman, K. S. (1997). Advances in the pathogenesis of periodontitis: summary of developments, clinical implications and future directions. Periodontology 2000.,14,216-48.

Page, R. C., \& Schroeder, H. E., (1976). Pathogenesis of inflammatory periodontal disease. A summary of current work. Laboratory investigation; a journal of technical methods and pathology, 34(3), 235-249.

Palombo, E. A., (2011). Extratos de plantas medicinais tradicionais e produtos naturais com atividade contra bactérias bucais: aplicação potencial na prevenção e tratamento de doenças bucais. Medicina alternativa e complementar baseada em evidências.

Paulino, N., Abreu, S. R. L., Uto, Y., Koyama, D., Nagasawa, H., Hori, H., \& Bretz, W. A. (2008). Efeitos antiinflamatórios de um composto biodisponível, Artepillin C, na própolis brasileira. European Journal of Pharmacology, 587 (1-3), 296-301.

Payne T. F. (1975). Why are white lesions white? Observations on keratin. Oral surgery, oral medicine, and oral pathology, $40(5), 652-658$.

Pedrazzoli, V., Kilian, M., Karring, T., \& Kirkegaard, E. (1991). Efeito do tratamento periodontal cirúrgico e não cirúrgico no estado periodontal e na microbiota subgengival. Journal of Clinical Periodontology, 18 (8), 598-604.

Pensin, N. R., Pensin, C., Miura, C. S. N., e Boleta-Ceranto, D. D. C. F. (2009). Efeito de pomada de própolis em orabase para tratamento de ulcerações aftosas recorrentes - um estudo piloto. Arquivos de Ciências da Saúde da UNIPAR, 13 (3).

Pereira E. M., de Silva J. L., Silva F. F., et al. (2011). Clinical evidence of the efficacy of a mouthwash containing propolis for the control of plaque and gingivitis: a phase II study. Evid Based Complement Alternat Med, 750-249.

Pereira, G. C. Á., (2014). Própolis: Conceitos, aplicabilidade e efeitos com ênfase na doença periodontal.

Petersen, P. E., \& Ogawa, H. (2005). Fortalecendo a prevenção da doença periodontal: a abordagem da OMS. Journal of periodontology, 76 (12), $2187-2193$.

Pihlstrom, B. L., McHuon, R. B., Oliphant, T. H., \& Ortiz-Campos, C. (1983). Comparação do tratamento cirúrgico e não cirúrgico da doença periodontal uma revisão dos estudos atuais e resultados adicionais após 6 anos e meio. Journal of Clinical Periodontology, 10 (5), $524-541$.

Ramfjord, S. P., Caffesse, R. G., Morrison, E. C., Hill, R. W., Kerry, G. J., Appleberry, E. A., \& Stults, D. L. (1987). 4 modalidades de tratamento periodontal comparadas ao longo de 5 anos. Journal of Clinical Periodontology, 14 (8), 445-452.

Ribeiro, M. R. G., Gualberto, A. M., Silva, M. A. S., Souza, S. F. C., Souza, E. M., \& Silva, V. C. (2015). Results of topical application of propolis extracts in reducing progression of periodontal disease. Revista Brasileira de Plantas Medicinais, 17(4), 915-921.

Samet, N., Laurent, C., Susarla, S. M., \& Samet-Rubinsteen, N. (2007). The effect of bee propolis on recurrent aphthous stomatitis: a pilot study. Clinical oral investigations, 11(2), 143-147.

Sanghani, N. N., Shivaprasad B. M., \& Savita, S. (2014). Health from the hive: propolis as an adjuvant in the treatment of chronic periodontitis-a clinicomicrobologic study. Journal of clinical and diagnostic research: JCDR, 8(9), ZC41.

Santos, C. A. L. D., Silva, A. M. R., Thomson, Z., Matsuo, T., Fernandes, K. B. P., \& Dezan, C. C. (2014). Prevalência e fatores associados àdoença periodontal em puérperas atendidas em maternidade pública em Londrina, Paraná. Espaço. saúde (Online), 37-46.

Santos, V. R., Pimenta, F. J. G. S., Aguiar, M. C. F., do Carmo, M. A. V., Naves, M. D., \& Mesquita, R. A. (2005). Oral candidiasis tratment with Brazilian ethanol propolis extract. Phytotherapy Research: An and Toxicological Evaluation of Natural Product Derivatives, 19(7), 652-654.

Sheiham, A., \& Netuveli, G. S. (2002). Doenças periodontais na Europa. Periodontology 2000, 29 (1), 104-121. 
Siegrist, B., \& Kornman, K. S. (1982). The effect of supragingival plaque control on the composition of the subgingival microbial flora in ligature-induced periodontitis in the monkey. Journal of dental research, 61(7), 936-941. https://doi.org/10.1177/00220345820610071001

Silva, M. A. Análise de biomarcadores salivares em pacientes com gengivite após uso de dentifrício $1 \%$ à base de própolis vermelha brasileira: um ensaio clínico randomizado.2019. 79 f. Tese (Doutorado em Ciências Farmacêuticas) - Faculdade de Farmácia, Odontologia e Enfermagem, Universidade Federal do Ceará, Fortaleza, 2019.

Slots, J. (2012) Low-cost periodontal therapy. Periodontol 2000,60,110-137.

Slots, J. (1979). Microflora subgengival e doença periodontal. Journal of Clinical Periodontology, 6 (5), 351-382.

Socransky, S. S., \& Haffajee, A. D. (2002). Dental biofilms: difficult therapeutic targets. Periodontology 2000, 28, 12-55.

Sparabombe, S., Monterubbianesi, R., Tosco, V., Orlisi, G., Hosein, A., Ferrante, L., \& Orsini, G. (2019). Eficácia de um anti-séptico bucal polyherbal totalmente natural em pacientes com periodontite: Um estudo randomizado controlado simples-cego. Fronteiras em fisiologia, 10, 632.

Stähli, A., Schröter, H., Bullitta, S., Serralutzu, F., Dore, A., Nietzsche, S., \& Eick, S. (2021). Atividade In Vitro da Própolis em Microrganismos Bucais e Biofilmes. Antibióticos, 10 (9), 1045.

Salvatori, C., Bernardo, M., Colonna, A., Gargari, M., Galeotti, F., Zaccaria, V., \& Volpi, N. (2021). Eficácia de um extrato padronizado de própolis na terapia periodontal não cirúrgica.

Samet N., Laurent C., Susarla S. M., \& Samet-Rubinsteen N. (2007). The effect of bee propolis on recurrent aphthous stomatitis: a pilot study. Clin Oral Investig; 11:143-47.

Sanghani, N. N., Shivaprasad, B. M. \& Savita, S. (2014). Health from the hive: propolis as an adjuvant in the treatment of chronic periodontitis-a clinicomicrobiologic study. Journal of clinical and diagnostic research: JCDR, 8, 9, ZC41.

Szliszka, E., A. Z. Kucharska, A. Sokoł-Łętowska, A. Mertas, 'Z. P. \& Czuba, W. Krol, (2013). "Chemical composition and anti-inflammatory effect of ethanolic extract of Brazilian green propolis on activated J774A.1 macrophages," Evidence-Based Complementary and Alternative Medicine

Tanasiewicz, M., Skucha-Nowak, M., Dawiec, M., Król, W., Skaba, D., \& Twardawa, H. (2012). Influence of hygienic preparations with a 3\% content of ethanol extract of Brazilian propolis on the state of the oral cavity. Advances in clinical and experimental medicine: official organ Wroclaw Medical University, 21(1), 81-92.

Teixeira, R. O. (2016). O uso de antimicrobianos na terapia periodontal: revisão. Artigo apresentado no curso de graduação em como requisito para obtenção do título de Cirurgião Dentista. Odontologia da Faculdade São Lucas. Porto Velho. Brasil.

Van Boeckel, T. P., Gandra, S., Ashok, A., Caudron, Q., Ggrenfell, B. T., Levin, S. A., \& Laxminarayan, R. (2014). Consumo global de antibióticos de 2000 a 2010: uma análise dos dados de vendas nacionais de produtos farmacêuticos. The Lancet infectious disease, 14 (8), 742-750.

Wlson Jr, T. G., Glover, M. E., Malik, A. K., Schoen, J. A., \& Dorsett, D. (1987). Perda dentária em pacientes de manutenção em clínica periodontal privada. Journal of periodontology, 58 (4), 231-235.

Yoshimasu, Y., Ikeda, T., Sakai, N., Yagi, A., Hirayama, S., Morinaga, Y., \& Nakao, R. (2018). Ação bactericida rápida da própolis contra Porphyromonas gingivalis. Journal of Dental Research, 97 (8), 928-936.

Yuan, X. J., Wang, Y. Y., Shi, B. Q., \& Zhao, Y. M. (2018). Effect of propolis on preserving human periodontal ligament cells and regulating proinflammatory cytokines. Dental traumatology: official publication of International Association for Dental Traumatology, 10.1111/edt.12411. Advance online publication. https://doi.org/10.1111/edt.12411

Ximénez-Fyvie, L. A., Haffajee, A. D., Som, S., Thompson, M., Torresyap, G., \& Socransky, S. S. (2000). O efeito da remoção profissional repetida da placa supragengival na composição da microbiota supra e subgengival. Journal of Clinical Periodontology, 27 (9), 637-647. 